\title{
Encouraging Undergraduate Class Participation: A Student Perspective
}

\author{
Nichole S. Wright, Marcia N. Gragg, \& Kenneth M. Cramer \\ University of Winsor
}

Undergraduate classes typically involve a professor lecturing to 100 or more students. Too often, this results in minimal opportunities for student participation. Positive reinforcement was used to promote student participation (i.e., defined as relevant comments or questions) in a second-year psychology class $(N=97)$. Class participation was measured for five weeks in two 80-minute lectures per week. Baseline was collected in two lectures. In the unaware phase for two lectures, paper tickets were given without explanation to students who participated. Students were then informed that tickets were given for class participation, and would be entered into a draw for gift certificates. Data were collected for four lectures in this informed condition. Final baseline consisted of two lectures with no tickets distributed. Student attendance was recorded. Frequency of instructor questions remained relatively consistent. Class participation rose from 38 relevant comments and questions per week during initial baseline, to 47 during the unaware phase, 52.5 during the informed phase, and 60 for final baseline. Positive reinforcement was associated with increased class participation overall, but with little change for students with high initial participation. Students said they enjoyed and benefited from the class participation activity.

\section{Introduction}

\begin{abstract}
A ctive class participation has been found to contribute to student learning (Michael, 2006). However, most undergraduate classes involve professors lecturing to large classes of 100 or more students. This format affords few opportunities for active engagement. Upper-level classes are often
\end{abstract}

smaller, and students can be encouraged to actively express their ideas. Even so, one student wrote in a class poll, "For many of us being in fourth year, we have gotten used to just listening in class and not participating much." I (Nichole) was inspired to conduct the current study while taking a 
fourth-year Behaviour Modification course taught by the second author (Marcia). Previously in my educational career, I rarely voiced my opinions or questions during class although I achieved excellent grades. Usually, only a few students per class willingly and frequently participated. In Behaviour Modification, Marcia reinforced student participation with paper tickets worth participation points. Points tallied throughout the semester contributed to $20 \%$ of the final grade. Positive reinforcers are stimuli presented immediately after a behaviour that increase the likelihood of the behaviour reoccurring, and backup reinforcers are delayed positive reinforcers paired with an immediate reinforcer (Cooper, Heron, \& Heward, 2007). In this class, the positive reinforcer was the participation point given immediately following a student participating, while the backup reinforcer was the percentage of the final grade.

In this situation, I began to eagerly share my ideas and insights. The ticket reinforcers in Dr. Gragg's class introduced me to the potential of active class participation. I began to question why participation was uncommon in larger undergraduate classes.

This study investigated whether positive reinforcement could increase participation in a larger second-year class. Class participation was defined as students' relevant questions or comments during lectures that contributed to whole group discussions. I used a token system to reinforce class participation, so students accumulated participation tickets for a draw to win prizes. We expected participation to increase when students were reinforced immediately and also with backup reinforcement.

\section{Method}

\section{Participants}

Participants were recruited from a second-year psychology class with 97 registered students in second to fourth year, at the University of Windsor. I was the teaching assistant, and interacted often with the course instructor.

\section{Procedure}

The course instructor and the Undergraduate Psychology Ethics Committee approved the study.

Class participation was defined as students' voluntary verbal comments, questions, or responses that contributed to the topic. Incorrect responses that attempted to contribute to class discussions were recorded as participation. Participation was not counted when students simply raised their hands, requested repetition of material, or answered a question directed to a specific student. During three lectures with nonstandard formats (i.e., group activity, brief movie, and discussion of the midterm and final paper), participation was recorded only for original comments or questions and not for 'housekeeping' talk.

Student attendance and the total number of participation responses for the class were recorded for each lecture. Frequency of participation was also recorded individually for each participant identified during baseline as an initial high-participating student.

The total number of instructor cues for participation was recorded for each lecture. This included the instructor asking questions to the group or giving opportunities for students to ask questions or comment about topics. This did not include instances when the instructor provided a scenario and asked students to simply raise their hands if they agreed or disagreed.

Before the study began, the instructor agreed to maintain a consistent level of opportunities for class participation in each lecture. Data on class participation were collected over five weeks in midsemester, with two lectures per week, in four phases. The initial baseline phase lasted for two lectures with no participation tickets. During the unaware phase for two lectures, tickets were awarded without explanation to students for participating. Participants were encouraged to keep the tickets. The informed phase lasted for four lectures after I explained the purpose of the tickets in class and on the course website. The final baseline phase lasted for two lectures, with no tickets awarded.

Participation tickets were $61 / 2 \times 10 \mathrm{~cm}$ pieces of coloured paper with two identical numbers. Half of each ticket was given to the participant, and the second half kept by the investigator. Numbering 
the tickets gave an accurate total of tickets distributed without personal information on who earned each ticket. After the study, students entered their participation tickets in a draw for a $\$ 20$ bookstore gift certificate or a $\$ 10$ coffee shop gift certificate.

The classroom was a lecture hall with a semicircle layout. I sat at the back to distribute participation tickets with minimum disruption. Quickly and efficiently locating participants' positions in the classroom to distribute tickets was challenging.

After the informed phase, I held a debriefing discussion, encouraging participants to share their comments or questions regarding their experience with the study. Participants received participation tickets for relevant comments or questions. The instructor completed a questionnaire regarding her experience with the study.

\section{Results}

Attendance at lectures ranged from 54 to 70 out of 97 registered students. As shown in Figure 1, instructor cues remained relatively consistent over the phases, with a slight increase in the final baseline. Frequency of class participation increased from baseline to the unaware phase, and again in week two of the informed phase, and stayed steady for the final baseline.

Baseline observation identified two active students, one male and one female, who initially offered more comments and questions. Individual participation rates for these active students remained relatively constant across phases (see Figure 1).

Students expressed mostly positive comments during the debriefing discussion. One student said, "after I read the online announcement, I started coming to class out of curiosity to see what the discussions would be about." Participants thought reinforcement increased their awareness of their classmates' comments and questions. Participants stated that listening to classmates increased their responsiveness to the lecture topic as well as questions and comments from other students and the instructor. They were attentive to questions posed by the instructor in order to contribute answers eligible for a participation ticket. Class participation allowed an opportunity to apply knowledge of the course material to personal experiences and consider information

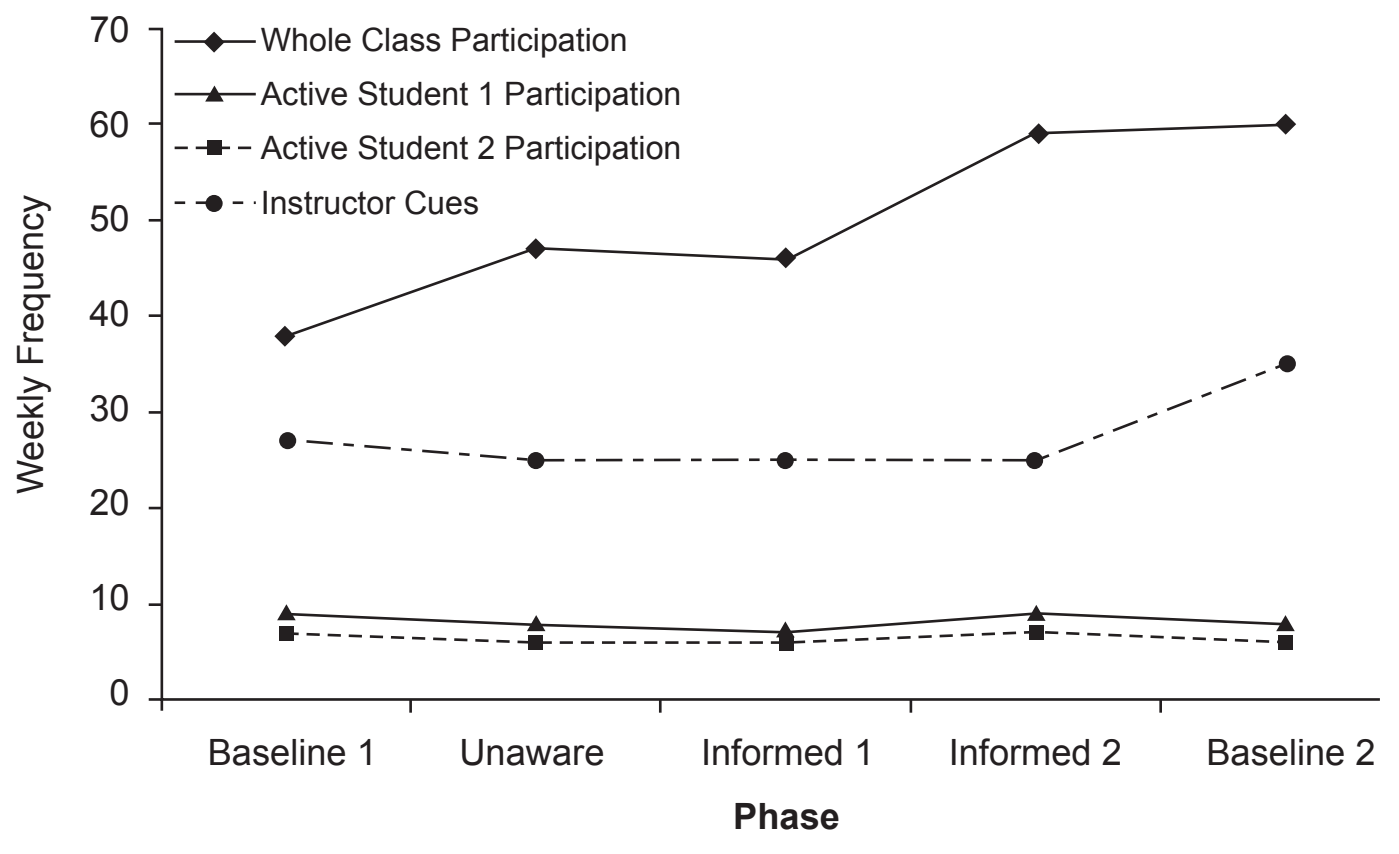

Figure 1

Class Participation and Instructor Cues 
from differing perspectives.

The instructor indicated, "the experience heightened [her] awareness of the quality of questions [she] was asking when lecturing, as opposed to the quantity. It motivated [her] to introduce more interesting, discussion-based questions, as opposed to simple yes/no questions."

\section{Discussion}

The purpose of this study was to determine if class participation increased with positive reinforcement. Participation was defined as participants' comments or questions in class that related to the course content. Student participation in class was reinforced immediately with participation tickets and a backup reinforcer of a draw for gift certificates. Class participation increased when the tickets were introduced and again after the purpose of the tickets were explained, and leveled off after reinforcement ended. Participants enjoyed and benefited from the class participation activity. Two active students, who showed high initial levels of participation, had relatively stable rates of participation across phases.

Several limitations in this study, including the small sample size and short intervention time, limit generalizability of the results. The level of class participation stayed relatively constant after reinforcement ended. It is possible that positive reinforcement resulted in a lasting increase in class participation, which was then maintained by students' overcoming their initial reluctance or by natural reinforcers such as instructor praise and positive reactions from classmates. However, it is also possible that factors unrelated to reinforcement, such as student interest, the novelty of the procedure, or naturally increasing comfort levels were at play (although the study began in mid-semester). Future research could include longer follow-up after tangible positive reinforcers were withdrawn: the 8:30 a.m. class time may have resulted in less participation simply because it was too early in the morning.

The definition of class participation in this study was limited to relevant verbal contributions during lectures. Future research could investigate other forms of participation, including attending office hours, emailing, or contributing to class online chat, discussion groups, or wikis.

Participants mentioned that the 'low-tech' method of distributing tickets for participation was somewhat distracting. Future research could investigate other methods, such as electronic means, to distribute positive reinforcers with less disruption. Perhaps the "clickers" that students currently use to indicate answers to instructor-designed multiplechoice questions in class (Beekes, 2006) could be adapted to reinforce open-ended voluntary class participation.

The instructor welcoming student participation may have provided a comfortable lecture atmosphere where participants were willing to talk in class. Questions from the instructor may have cued students to respond, leading to a participation ticket. University education aims to promote independent active learning however, a lecture lacking active engagement ultimately positions the student as a passive learner waiting to accumulate knowledge from a superior, rather than an active constructor of knowledge (Michael, 2006). Lecture engagement is beneficial for both students and professors. Students' quality of education may improve if they are encouraged to communicate with their professors and students in class.

In this study, participation levels for active or initially high-participating students remained relatively constant whether or not participation tickets were awarded. During the debriefing discussion, one active student mentioned the issue of internal versus external motivation, and stated, "I did feel that receiving an external reward for my internal motivation to participate did minutely deter my willingness to participate." Some educators believe that students should participate without positive reinforcement, or that reinforcement may deter interested students from participating and decrease interest for externally motivated students when reinforcement ends. However, recent reviews of the research (Cameron, 2005; Henderlong \& Lepper, 2002) conclude that positive reinforcement increases intrinsic motivation under many conditions; for example, when reinforcers are given for low-interest tasks, they are positive feedback or praise, and tangible reinforcers are given 
for high-interest tasks and tied to successfully achieving various standards of performance.

\section{Conclusion}

Positive reinforcement was associated with increased class participation in a second-year university psychology class. Two students with high participation prior to the study maintained consistent participation over five weeks. Our hope is that encouraging participation earlier in students' university careers will result in lasting increases in engagement in later courses. For me (Nichole), tangible reinforcement, generalized to natural reinforcers in subsequent undergraduate and graduate classes, has maintained my active engagement and intrinsic motivation to participate. From a student perspective, encouragement to participate can ultimately affect the quality of education.

\section{References}

Beekes, W. (2006). The millionaire method for encouraging participation. Active Learning in Higher Education, 7, 26-36.

Cameron, J. (2005). The detrimental effects of reward hypothesis: Persistence of a view in the face of disconfirming evidence. In W. L. Heward et al. (Eds.), Focus on behavior analysis in education: Achievement, challenges and opportunities (pp. 304-315). Upper Saddle River, NJ: Pearson Education, Inc.

Cooper, J.O., Heron, T.E., \& Heward, W.L. (2007). Applied behavior analysis (2nd ed.). Upper Saddle River, NJ: Pearson Education, Inc.

Henderlong, J. \& Lepper, M.R. (2002). The effects of praise on children's intrinsic motivation: A review and synthesis. Psychological Bulletin, $128,774-795$.

Michael, J. (2006). Where's the evidence that active learning works? Advances in Physiology Education, 30, 159-167.

\section{Biographies}

Nichole S. Wright is a masters candidate in SpeechLanguage Pathology in the Department of Communication Sciences \& Disorders at Wayne State University, Michigan. Her scholarly interests are in early language development, and Speech and Language disorders.

Marcia N. Gragg is an Assistant Professor in the Department of Psychology at the University of Windsor, Ontario. Her scholarly interests are in Spectrum Disorders, behavioural interventions, and applying best practices from behavioural research in the community.

Kenneth M. Cramer is a $3 \mathrm{M}$ Teaching Fellow and Professor in the Department of Psychology at the University of Windsor, Ontario. His interests are in educational psychology, the impact of university rankings on university students, and lecture engagement strategies. 